\title{
Revisiting a Standard Theory of Cooperatives: A Behavioral Economics Perspectives
}

\author{
Nyankomo Marwa \\ University of Stellenbosch Business School, South Africa \\ Email: nyankomo.marwa@gmail.com
}

Doi:10.5901/mjss.2014.v5n6p117

\begin{abstract}
The current economic understanding of the standard theory of cooperative organization is inclined towards neoclassical rational choice theory. While this is useful in predicting the behavior of individual under perfect information and less uncertain world, empirical evidence shows that, more often, decision-makers operate in a complex and uncertain environment, and the information available is far from perfect. This paper points out the existing limitations of the standard theory of cooperatives. It then proposes the behavioral rational choice model, which incorporates behavioral aspects into the standard neoclassical model. It concludes that this proposed model improves our insights and understanding of the behavior of cooperative organizations.
\end{abstract}

Keywords: Cooperatives, Neoclassical Rational Choice Theory, Behavioral Economics

\begin{abstract}
"It has long appeared to many people that economics is the most successful of the social sciences. It has assumed that people are motivated by money and by the possibility of making a profit, and this has allowed it to construct formal, and often predictive, models of human behavior. This apparent success has led many other social scientists to cast envious eyes in its direction. They have thought that if they could only follow the methods of economics they could achieve similar successes in their own studies. These sociologists and political scientists have tried to build theories around the idea that all action is fundamentally 'rational' in character and that people calculate the likely costs and benefits of any action before deciding what to do. This approach to theory is known as rational choice theory." (Scott, 2000: pp.2)
\end{abstract}

\section{Introduction}

The evolution of cooperative organizations can be traced back to the 1700 s, with a more formal and structured cooperative emerging in 1844 under the Rochdale Society of Equitable Pioneers in England (Ortmann and King, 2007). A new wave of cooperative movement and cooperative organization arose during $19^{\text {th }}$ century in North America and other parts of the world. Since then, agricultural marketing cooperatives have played a dominant role, with the evolution of these rooted in the emergence of commercial agriculture during $19^{\text {th }}$ century. Different schools of thought on cooperative organization were developed in North America and Europe. The American school of thought is more inclined towards pragmatism, in contrast to the European school that emerged as a result of social reforms and associated philosophies of the times (Torgerson, Reynolds \& Gray, 1997).

In terms of methodological development, intellectual work in the field of cooperatives is fairly young, with most of the progress concentrated in the second half of the 20th century (Emilianoff, 1942; Robtka, 1947; Philips 1953; and Helmberger \& Hoos; 1962). Among the early work, Helmberger's and Hoos's (1962) paper was regarded as seminal in the theory of cooperatives (Staaz, 1984). These authors used neoclassical theory of the firm to develop both short run and long run model of cooperatives. More specifically, marginal analysis was applied to analyze the cooperative's objective which is to maximize the benefits to members (Ortamann and King, 2007). A series of subsequent theoretical studies have been conducted in the last three decades to extend Helmberger's theory and one of the different approaches includes the coalition and contract nexus approach to cooperative theory (Cook et al, 2004; and Staatz, 1984).

Most of the work to date on the standard theory of cooperatives is anchored in the neoclassical theory of rational choice as an analytical framework. While such a framework is widely used in economic modeling, recent empirical evidence from behavioral science shows that actual choice behavior usually departs widely from the behaviors predicted by the axioms of perfect rationality (Simon, 1994; Kahneman, Slovic and Tversky, 1982; and Simon, 1955). Despite the growing literature in the field of behavioral economics, none of the studies on the theory of cooperative behavior explicitly included behavioral aspects into the modeling framework that was used. Thus, the objective of this essay is to revisit the 
standard theory of cooperative organizations, highlighting the existing gap(s) and proposing possible improvement(s)/extension(s) based on the behavioral economics approach. The changes suggested contribute to advancing our understanding of how to model the actual behavior of the actors in the cooperatives context and improving our descriptive and predictive results about the behavior of cooperative organizations. These results are particularly important for management and policy makers, who are required to understand the possible outcomes and ramifications of their decisions.

The rest of the essay is organized as follows: Section 2 presents a review of the standard theory of cooperatives and an overview of behavioral economics; Section 3 presents rational choice theory. Section 4 presents fundamental assumptions underlying the standard theory of cooperatives, discusses its limitations and proposes a possible change, namely extension of the model. Section 5 presents the summary and concluding remarks.

\section{Standard Theory of Cooperative}

Cooperatives are organizations whose members are both owners and users of the organizational services and whose main objective is to maximize members' welfare. In contrast, in standard investors owned firms (IOFs), the owners are not necessarily the users of the services provided and seek to maximize profit. Such uniqueness in the characteristics of cooperatives implies that the standard theory of the firm, which was mainly developed to understand the behaviors of IOFs, does not precisely capture the behavior of cooperatives, at least in its original version. In response to such limitations, different theoreticians have proposed diverse extensions of the neoclassical theory of the firm to explain the behaviors of cooperative organizations. There are several versions of cooperative theory that base their analytical framework on the neoclassical rational choice theory. However, the majority of these theories can be generally categorized into three major groups, namely: (i) the cooperative as a firm; (ii) the cooperative as a coalition; and (iii) the cooperative as a nexus of contracts (Cook et al, 2004).

Theoretical work on cooperatives as firms assumes that a cooperative is a separate firm trying to maximize a single objective function. This objective function may be members' welfare, joint profit or both, depending on the nature and member composition of the cooperative. Many empirical and theoretical works in this cluster have been conducted to address different problems arising in cooperative organizations. Such work includes spatial pricing modeling to take into account the effect of member heterogeneity, and mixed duopoly between cooperatives and IOFs to understand the justification put forward for favorable public policy towards cooperatives (Sexton; 1990; and Tennback, 1995). A detailed compilation of the existing studies on this category is available in Cook et al, (2004). All of the studies in this school of thought have used a standard neoclassical rational choice theory as a building block in their analytical framework. While such a framework is widely used in economic modeling, this paper will demonstrate its limitation and propose an alternative approach to modeling the cooperative organization.

Another group of theoreticians and modelers has applied game theory to view cooperatives as a coalition of utilitymaximizing subgroups. Based on this approach, cooperatives seek to maximize benefits (gains) from a joint action by a potential coalition of members. This is achieved through bargaining among members about how benefits are distributed (Cook et al, 2004; Zusman \& Rausser, 1994; Bourgeon \& Chamber, 1999; Fulton \& Giannakas, 2000). Similar to the approach used by the first group of modelers, this approach also assumes that the behaviors of cooperatives follow the neoclassical rational choice model.

There is also another group of theoreticians who view cooperatives as a nexus of contracts. This approach views business relationships among stakeholders as contractual relationships. It is basically a loose connection of agency theory, transaction cost economics and property right-incomplete contract theory. A detailed discussion of this approach can be accessed through different authors' works (for example, Eilers and Hanf, 1999; and Hendrikse and Veerman, 2001). As with the other two categories, the theoretical framework in this subcategory is built on the neoclassical rational choice model. The next section introduces neoclassical rational choice theory and its limitations.

\section{Rational Choice Theory, Behavioral Economics and the Standard Theory of Cooperatives}

The rational choice theory posits that economic actors are rational and are seeking to maximize their utilities or benefits (Green, 2002). From this perspective, behavior is expected to conform to the following axioms: an agent/individual faces a known set of alternative choices; the individual's choices are complete; preferences are transitive and, given different options, the individual will choose the most preferred alternative (Green, 2002). Thus, in economics, rational behavior implies a behavior that is in accordance with the above axioms.

As explained in Section 2, the standard theory of cooperative organizations uses rational choice theory to explain 
the behavior of cooperative organizations. Within the rational choice framework, individuals are assumed to have certain preferences and face constraints. However, empirical evidence shows that the actual choice behavior usually departs widely from the behaviors predicted by the axioms of perfect rationality (Simon, 1994; and Kahneman, Slovic and Tversky, 1982). Moreover, decision-makers within organizations and business firms are highly concerned with the discovery of choice alternatives and frequently seek satisfactory rather than optimal choices, in contrast to optimal choice being used in neoclassical theory (Simon, 1955; Jone, 1999; and Cyert and March, 1963). Furthermore, the standard neoclassical utility function focuses more on pecuniary benefits as an instrument for influencing human behaviors. Recent studies have shown that non-pecuniary benefits, such as identity, issue framing, endowment effects, altruism, norms and reciprocity also play an important role in influencing human behavior (Akerlof and Kranton, 2000 and 2005; Ostrom, 2000; and Chao, 2007).

Gino and Pisano (2007) argue that, by most measures, the rational choice model can be applied successfully to choice problems without uncertainty. The caveat behind the real world behavioral context is that decision-making environments are complex; there is plenty of uncertainty; the information available is always far from being perfect and these environments are values-driven. Decision-makers are always faced with cognitive limitations and the interdependence among these factors is important for final behavioral and decision outcome (Fischer, 2003; Stone, 1997; Simon, 1997; Jones and Baumgartner, 2005; and Functowics, 2002).

Moreover, empirical research findings from behavioral economists have demonstrated that the rational choice model systematically predicts behavior less well in specific circumstances (Gion and Pisano, 2007). For example, Kehneman and Tversky (1984) demonstrated that the way in which a choice is framed strongly affects the choice outcome that results. In contrast to traditional economics, behavioral economics does not assume "that individuals, firms, and policy-makers are purely self-interested and make choices that are fully rational and use all available information. It rather recognizes that actual choices do not always fit within the standard model (e.g. people might care about equity) and that agents may employ heuristics instead of optimally using the available information" (UT, 2011). Based on this view point, it is important to understand the actual behavior of decision-makers, whether these are individuals, firms or policy-makers, for appropriate policy and management response. Despite the growing literature on behavioral economics, according to the researcher's knowledge, none of the modelers in the standard theory of cooperatives has explicitly incorporated the behavioral aspect into their modeling framework.

\section{Neoclassical Rational Choice Theory and Proposed Extension}

This section presents an explicit utility function, which is a major benchmark for the optimization problem underlying the neoclassical rational choice theory. It further demonstrates the existing discrepancy in problem formulation using the standard theory of cooperatives in relation to empirical anomalies, as mentioned by behavior economists in section 2 . Using the behavioral economics approach, some suggestions are provided on how to improve traditional cooperative theory by incorporating non-pecuniary factors in the model. Most of these non-pecuniary factors are behavioral factors such as identity, framing, cognitive dissonance, altruism, herding behavior, conformance to social norms and fairness.

In standard neoclassical rational choice theory, an individual/ agent would have a utility depending on income (which is roughly a sum of pecuniary benefits) and he/ she will derive disutility from all other factors, which will result in the individual incurring a cost, such as effort, paying for the services or a membership fee. In the context of cooperatives, members will join and remain loyal to the cooperative if the perceived monetary benefits are higher than the expected cost of joining and remaining active members of the organization. If we assume that an individual/ agent has log additive utility function in income, then the neoclassical utility function can be represented mathematically as follows:

$U(Y, X \mid$ rational $)=\operatorname{In}(Y)-X$

Where $Y$ is a vector of monetary benefit from participating in the activity or organization; and $X$ is a vector of the activities that will decrease his/ her utility by participating in the activity.

The actual neoclassical problem will then be for an individual/ agent to maximize his/ her utility subject to given constraints. This approach of problem formulation ignores behavioral factors in the analysis. Such omission may lead to systematic bias in the conclusions derived from this analytical framework. Depending on the nature of the influence by non-economic (behavioral) variables the conclusion may suffer from either downward bias or upward bias and, in some cases, there may be an incorrect prediction altogether.

For instance, when modeling workers' compensation, Arkerlof and Kranton (2005) demonstrated that the identity of an individual has a significant moderating effect on the amount of compensation required to induce him to work at the optimal effort. The variability of the effort and, hence, compensation levels, depend not only on economic incentives but also on whether the worker identifies himself as an outsider or insider with respect to the belongingness to the 
organization. There is also a moderating effect due to the interaction between monetary and behavioral incentives. To improve the neoclassical utility model, this paper adapted the Akerlof and Kranton model, which was applied in a special case of identity, to analyze workers' compensation in a more general "behavioral rational utility function".

In what we call a generalized behavioral rational utility function, we assume that cooperative members have a logadditive utility function in pecuniary benefit $(Y)$ and non-pecuniary benefits $(Z)$, which are mainly sociological and psychological factors. A vector of economics incentive $(Y)$, a vector of cost variables $(X)$, a vector of non-economic incentives ( $Z$ ) and a category dummy (c) are incorporated within the framework of bounded rationality. Alpha is the parameter that captures the intensity underlying the incentives trigger within an individual (for simplicity it is normalized to 1); i.e. a captures the propensity of utility derived from pecuniary benefits and 1-a captures the propensity of utility derived from sociological and psychological benefits. Beta is the parameter that captures the moderating effect between economic and non-economic incentives. The generalized behavioral utility function can be represented algebraically as follows:

$U_{i}(Y, X, Z \mid$ bounded rational $)=\alpha \operatorname{In}(Y)+(1-\alpha) Z+b(Z I n Y)-X-\left(\alpha\left(X^{*}(Y)-X\right)+(1-\alpha)\left(X^{*}(Z)-X\right)\right)$

Where $X^{*}$ is the optimal (least) cost for participating in the socio-economic activity while $X$ is the actual cost incurred by an individual. The first term (alnY) in equation 2 captures the pecuniary benefits; the second term ((1-a)Z) captures the non-pecuniary benefits, the third term $(b(Z \ln Y))$ is the interaction term for the pecuniary and non-pecuniary benefits; the fourth term $(X)$ represents the disutility due to the cost incurred and the last term captures the disutility by diverging from the optimal, socially accepted norms $\left(X^{*}\right)$.

The modified behavioral utility function provides a more flexible way of modeling the actual behavior of the stakeholders involved in cooperative organizations, at least from the normative analysis. Incorporating behavioral aspects into our modeling framework helps to improve the capability of the economic sciences in providing richer insights into how to understand the behavior of economic agents and cooperative organizations in particular. A recent study has shown that identification with strategic networks leads to internalization of network norms. The resulting normative frame of reference affects the behavior of agents through encouraging cooperatives since any normal breaking behavior will be accompanied by an identity cost.

Other literature has demonstrated that the relationship between cooperatives and members is very important. Members' commitment to cooperatives is what differentiates cooperatives from other organizational forms (Fulton, 1999; and Fulton and Giannakas, 2001). Apart from the economics incentives, other behavioral factors such as cognitive dissonance have been mentioned as acting as significant buffers against members' attrition and increased loyalty (Lampros, 2008). Thus, the incorporation of cognitive dissonance and other behavioral factors may help management to understand better the reasons behind members' attrition, compared to prediction based on the standard neoclassical theory.

The main challenge facing the behavioral approach in economic analysis is the fact that it has a normative bent. Since most of the behavioral factors are value-based and more subjective than objective, this makes empirical estimation and verification difficult in some instances. In addition, due to social-cultural heterogeneity and diversity in norms across communities, it is difficult to formulate a more unified recommendation. Many of the recommendations made using model 2 may thus need to be context-specific.

\section{Conclusion}

The current economic understanding of the standard theory of cooperative organization is inclined towards neoclassical rational choice theory. While this theory is useful in predicting the behavior of individuals in conditions of perfect information and less uncertainty, empirical evidence shows that often decision-makers operate in a particularly complex and uncertain environment, and that the information available is far from perfect. Moreover, human beings are not necessarily always selfish, as would be predicted by the standard rational choice model. In addressing these limitations of the standard rational choice model, the behavioral rational choice utility model, which incorporates the behavioral aspect, has been developed. In appreciating the complexity of the decision-making environment, bounded rationality is assumed instead of a purely rational approach. It is concluded that since the standard theory of cooperatives is based on the neoclassical utility theory, it needs to be modified to incorporate behavioral factors. This is likely to improve our insights into and understanding of the behavior of cooperative organizations. 


\section{References}

Akerlof, G and Kranton, R . (2005). Identity and the economics of organizations. Journal of Economic Perspectives 16: 9-32.

Akerlof,G.A and Kranton, R.(2002). Economics and Identity. The Quarterly Journal of Economics, Vol CXV (3): 715-749.

Burgeon, J.M and Chambers, R.G. (1999). Producer Organizations, Bargaining, and Asymmetric Information. American Journal of Agricultural Economics, 81(3):602-09.

Chao, G. (2007). Mentoring and Organizational Socialization: networks for work adjustment in Belle Rose Ragins and Kathy Kram, The Handbook of Mentoring at Work Sage: California (pp. 179-196).

Cook, M., Chaddad F.R., and lliopoulos, C.(2004). Advances in Cooperative Theory since 1990: A Review of Agricultural Economics Literature. In Restructuring Agricultural Cooperatives by Hendrikse G.W.J.

Cyert, R.M and March, J.G.(1963). A behavioral theory of the firm. Engewood Cliffs, NJ: Prentice - Hall.

Eilers,C. and C.H.Hanf.(1999).Contract between Farmers and Farmers' Processing Cooperatives : A Principal Agent Approach for the Potato Starch Industry. In G.Galizzi and L.Venturini (eds), Vertical Relationships and Coordination in the Food System, Heidelberg: Physica, pp.267-84.

Emelianoff IV .(1942). Economic theory of cooperation: Economic structure of cooperative organizations. Reprinted by the Center for Cooperatives, University of California, Davis, California, USA, 1995.

Fischer, Frank. (2002). Reframing Public Policy. Oxford: Oxford University Press.

Fulton, M. E. (1999). Co-operatives and Member Commitment. The Role of Co-operative Entrepreneurship in the Modern Market Environment. The Finnish Journal of Business Economics, 4: 418-437.

Fulton, M. E. and Giannakas, K. (2001). Organizational Commitment in a Mixed Oligopoly: Agricultural Co-operatives and InvestorOwned Firms. American Journal of Agricultural Economics, 83(5): 1258-1265.

Fulton, M.E.(2000).Organizational Commitments in a Mixed Oligopoly : Agricultural Cooperatives and investors-Owned Firms. American Journal of Agricultural Economics, 83(5):1258-1265.

Funtowicz, S. (2002). Post-Normal Science: Science and Governance under Conditions of Complexity. Institute for the Protection and Security of the Citizen, 17, 63-74.

Gino, F., and Pisano, G. (2007). Toward a Theory of Behavioral Operations. HBS Working Paper Number: 07-096.

Green, S.L.(2002). A rational Choice Theory: An overview. Baylor University Faculty Development Seminar on Rational Choice Theory.

Helmberger P.G \& Hoos S. (1962). Cooperative enterprise and organization theory. Journal of Farm Economics 44:275-290.

Hendrikse,G.W.J and Veerman C.P.(2001). Marketing Cooperatives: An incomplete Contracting perspective . Journal of Agricultural Economics, 52(1):53-64.

Jones, B. (1999). Bounded Rationality. Annual Review of Political Science 2: 297-331.

Jones, B. and F. Baumgartner. (2005). The Politics of Attention: How Government Prioritizes Problems. Chicago: The University of Chicago Press.

Kahneman, D., and Tversky, A . (1984). Choices, values and frames. American Psychologist 39: 341-50.

Kahneman, D., Slovic, P., and Tversky, A. (1982). Judgment under Uncertainty: Heuristics and Biases. Cambridge University Press.

Lamprinakis, L . (2008). Cognitive Dissonance, Mental Frames and the Financial Value of Agricultural Co-operatives. PhD Thesis , University of Saskatchewan .

North, D. (1990). Institutions, Institutional Change and Economic Performance. Cambridge: Cambridge University Press.

Ortman, G.F., and King R.P.(2007). Agricultural Cooperatives I: History, Theory and Problems. Agrekon, Vol 46, No 1.

Phillips, R .(1953). Economic nature of the cooperative association. Journal of Farm Economics 35:74-87.

Robotka, F. (1947). A theory of Cooperation. Journal of Farm Economics 29:94-114.

Scott, J. (2000). Rational Choice Theory. In "Understanding Contemporary Society: Theories of The Present", edited by G. Browning, A. Halcli, and F. Webster. Sage Publications.

Sexton, R.J.(1990). Imperfect Competition in Agricultural Markets and the Role of Cooperatives: A Spatial Analysis. American journal of Agricultural Economics, 72(30): 709-20.

Simon, H. (1955). A Behavioral Model of Rational Choice. Quarterly Journal of Economics 69: 99-118.

Simon, H. (1997). Administrative Behavior: A Study of Decision-Making Processes in Administrative Organizations. (4th ed). New York: The Free Press.

Staaz, J.M . (1984). Farmer Cooperative Theory: Recent Developments. USDA Agricultural cooperatives, ACS Research Report number 84.

Stone, D. (1997). Policy Paradox: The Art of Political Decision Making. New York: W.W. Norton \& Company.

Tennbakk, B.(1995). Marketing Cooperatives in Mixed Duoplies . Journal of Agricultural Economics, 46(1):33-45.

Torgerson,E.R, Reynolds.J.B and Gray, T.W. (1997). Evolution of Cooperative Thoughts, Theory and Purpose. Presentation: Conference on "Cooperatives: Their Importance in the Future of the Food and Agricultural System," Food and Agricultural Marketing Consortium, Las Vegas, NV, January 16-17.

University of Tennessee. (2011). What do Behavioral Economist Do. Available online at http://econ.bus.utk.edu/berg/berg.htm.

Zusman,P and Rauser, G.C . (1994). Inter-organizational Influence and Optimality of collective Action. Journal of Economics behavior and Organization, 24: 1-17 
